\title{
Effect of Postural Changes on Resting Metabolic Rate and Substrate Utilization
}

\section{Postüral Değişimin Dinlenik Metabolik Hız ve Yakıt Kullanımı Üzerine Etkisi}

\author{
Tahir Hazır ${ }^{1}$, Gökhan Denizli ${ }^{1}$, Süleyman Ulupınar ${ }^{1}$, Nihat Özgören ${ }^{1}$, Mustafa Can Eser ${ }^{1}$, Funda \\ Büşra Dumankaya ${ }^{2}$, Ayşe Kin İşler ${ }^{1}$ \\ ${ }^{1}$ Department of Exercise and Sport Sciences, Faculty of Sport Sciences, Hacettepe University, Ankara, Turkey \\ ${ }^{2}$ Department of Recreation, Faculty of Sport Sciences, Hacettepe University, Ankara, Turkey
}

\section{T. Hazır \\ 0000-0002-0048-0281 \\ G. Denizli \\ 0000-0003-2964-7601 \\ S. Ulupınar (iD \\ 0000-0002-9466-5278 \\ N. Öngören \\ 0000-0002-4666-7252 \\ M. C. Eser \\ 0000-0003-1771-861X \\ F. B. Dumankaya 0000-0002-7356-8487 \\ A. K. İșler (iD \\ 0000-0001-9651-2067}

Geliş Tarihi / Date Received: 08.03.2018

Kabul Tarihi / Date Accepted: 10.05.2018

Yayin Tarihi / Date Published: 10.08.2018

\section{Yazışma Adresi /}

Corresponding Author:

Tahir Hazır

Egzersiz ve Spor Fizyolojisi

AD, Spor Bilimleri Fakültesi, Hacettepe Üniversitesi, Ankara, Turkey

E-mail: thazir@hacettepe.edu.tr

\section{ABSTRACT}

Objective: While supine position is the classical method to measure resting metabolic rate (RMR), the effects of postural changes on RMR is not clear. The aim of this study is to examine the effect of postural changes on RMR and substrate utilization.

Material and Methods: RMR was measured in 23 sedentary male subjects (age: $26.7 \pm 5.8 \mathrm{yr}$ ) after an overnight fast for $10 \mathrm{~min}$ in random order for supine, sitting and standing positions. An automated gas analysis system was used to measure oxygen consumption $\left(\mathrm{VO}_{2}\right)$, carbon dioxide production $\left(\mathrm{VCO}_{2}\right)$, minute ventilation $\left(\mathrm{V}_{\mathrm{E}}\right)$, and heart rate (HR) to determine RMR. RMR was calculated with Weir's formula, whereas rates of carbohydrate $(\mathrm{CHO})$ and free fatty acid (FFA) utilization were calculated with Frayn's formula. One way ANOVA with Bonferroni post hoc test was used to calculate the effect of postural changes on variables, and one sample t-Test was used to identify the difference between resting $\mathrm{VO}_{2}$ and $1 \mathrm{MET}$ levels.

Results: RMR values measured in supine and sitting positions were similar, both of which were significantly lower than those measured in the standing position $(p<0.01)$. Both $V_{E}$ and $H R$ values measured in all three positions were different $(p<0.01) . V_{2}$ levels measured in supine and sitting positions were significantly lower than 1 MET (3.5 $\left.\mathrm{ml} . \mathrm{kg}^{-1} \cdot \mathrm{min}^{-1}\right)(\mathrm{p}<0.01)$, while $\mathrm{VO}_{2}$ measured in standing position was similar with 1 MET ( $p>0.05$ ). Rate of $\mathrm{CHO}$ utilizationwas similar in sitting and standing positions, whereas in the supine position, this rate was significantly higher than in the sitting position $(p<0.01)$. Conversely, rate of FFA utilization was significantly different in all three positions $(p<0.01)$. The lowest rate of FFA utilization was measured in the supine position, while the highest was measured in the standing position.

Conclusion: Findings of this study indicated that postural change significantly affected RMR and activity of the cardio-pulmonary system. In addition, substrate utilization has shifted from $\mathrm{CHO}$ to FFA in accordance with postural changes.

Keywords: Posture, resting metabolic rate, heart rate, minute ventilation, substrate oxidation

öz

Amaç: Dinlenik metabolik hızın (DMH) ölçümünde yatar pozisyon klasik yöntem olmakla birlikte, postüral değişimin DMH üzerindeki etkisi açık değildir. Bu çalışmanın amacı postüral değişimin DMH ve yakıt kullanımı üzerine etkisini incelemektir.

Gereç ve Yöntemler: Toplam 23 sedanter erkek (Yaş: $26.7 \pm 5.8$ yıl, boy: $177.4 \pm 6.8$ $\mathrm{cm}$, vücut ağırlı̆ı̆: $77.2 \pm 10.9 \mathrm{~kg}$ ) deneğin bir gecelik açlık sonrasında rastgele sırada 
yatar, oturur pozisyonda ve ayakta $10 \mathrm{dk}$ süre ile DMH'leri ölçüldü. DMH'yi belirlemek için oksijen tüketimi $\left(\mathrm{VO}_{2}\right)$, karbondioksit üretimi $\left(\mathrm{VCO}_{2}\right)$, dakika ventilasyonu $\left(\mathrm{V}_{\mathrm{E}}\right)$ ve kalp atım hızı ölçüldü. $\mathrm{DMH}$ son 5 dk'da ölçülen ortalama $\mathrm{VO}_{2}$ ve $\mathrm{VCO}_{2}$ 'den Weir'in formülüyle kcal.dk ${ }^{-1}$ olarak ölçüldü. Karbonhidrat $(\mathrm{KH})$ ve serbest yağ asidi (SYA) kullanım hızı ise Frayn'ın formülünden g.dk ${ }^{-1}$ olarak hesaplandı. Postüral değişimin DMH üzerine etkisi için tekrarlı ölçümlerde tek yönlü varyans analizi ve Bonferroni post hoc testi, dinlenik $\mathrm{VO}_{2}$ 'nin 1 MET değerinden farkı için tek örneklem tTesti kullanıldı.

Bulgular: Yatar ve oturur pozisyonda ölçülen DMH benzeri ve her ikisi ayakta ölçülenden anlamlı derecede düşüktü $(p<0.01)$. Üç pozisyonda ölçülen hem $V_{E}$ hem de $K A H$ anlamlı derecede birbirinden farklı idi $(p<0.01)$. Yatar ve oturur pozisyonda ölçülen $\mathrm{VO}_{2}\left(\mathrm{ml} \cdot \mathrm{dk}^{-1} \cdot \mathrm{kg}^{-1}\right), 1 \mathrm{MET}\left(3.5 \mathrm{ml} \cdot \mathrm{kg}^{-1} \cdot \mathrm{dk}^{-1}\right)$ değerinden anlamlı derecede düşük $(p<0.01) ;$ ayakta ölçülen $\mathrm{VO}_{2}$ ile benzer ( $p>0.05$ ) bulundu. Oturur pozisyonda ve ayakta elde edilen $\mathrm{KH}$ kullanım hızları benzer $(p>0.05)$, yatar pozisyonda ise oturur pozisyondan anlamlı derecede yüksekti $(p<0.01)$. Buna karşılık. SYA kullanım hızı üç pozisyonda da anlamlı derecede birbirinden farklı idi $(p<0.01)$. En düşük SYA kullanım hızı yatar pozisyonda, en yüksek ise ayakta ölçüldü.

Sonuç: Bu çalışmanın bulguları postüral değişimin DMH'ı ve kardiyo-pulmoner sistemin aktivitesini önemli ölçüde değiştirdiğini, yakıt kullanımının postüre bağlı olarak KH'dan SYA'ne doğru kaydığını göstermiştir.

Anahtar sözcükler: Postür, dinlenik metabolik hız, kalp atım hızı, dakika ventilasyonu, substrat oksidasyonu

Available at: http://journalofsportsmedicine.org and http://dx.doi.org/10.5152/tjsm.2018.103

Cite this article as: Hazir T, Denizli G, Ulupinar S, et al. Effect of postural changes on resting metabolic rate and substrate utilization. Turk J Sports Med. 2018;53(4):142-51.

\section{GíRiș}

Dinlenik metabolik hız (DMH) dinlenik şartlarda yaşamsal faaliyetler için vücudun gereksinim duyduğu enerji miktarı olarak tanımlanır (1-2). DMH günlük toplam enerji harcamasının en büyük bölümünü oluşturur ve sedanter bireylerde günlük enerji harcamasının \%60-75'ine, fiziksel olarak aktif bireylerde veya sporcularda ise $\% 50$ 'sine karşılık gelir (3). DMH, vücut ağırlığı ve kompozisyonunun korunmasında önemli bir role sahip olduğu için hem sağlıklı bireylerde, hem de özellikle hastane ortamındaki hastalarda enerji ihtiyacını belirlemek için kullanılmaktadır.

Bunun yanında DMH egzersiz şiddetinin doğru olarak belirlenmesinde ve belirli bir şiddette yapılan egzersizde harcanan enerjinin hesaplanmasında da kullanılmaktadır (4). $\mathrm{Bu}$ nedenle endirekt kalorimetrik yöntemle $\mathrm{CO}_{2}$ tüketimi ve $\mathrm{CO}_{2}$ üretimi) DMH'nin doğru olarak ölçülmesi önem taşımaktadır. DMH'nin doğru ve güvenilir olarak ölçülmesine ilişkin çalışmalardan elde edilen bulgular besinlerin termik etkisi, alkol, kafein ve diğer uyarıcılar, dinlenme periyodu, fiziksel aktivite ve egzersiz, ölçüm süresi ve ölçümde kullanılan metabolik sistemler ve vücut pozisyonu gibi birçok faktörün DMH'yi önemli ölçüde etkilediğini göstermiştir (5).
DMH ölçümünde yatar pozisyon klasik yöntem olmakla birlikte, postüral değişimin $\mathrm{DMH}$ üzerindeki etkisi açık değildir. Örneğin 22 genç erkek ve kadında yapılan bir çalışmada katılımcıların 1/3'ünde oturur pozisyonla karşılaştırıldığında, ayakta ölçülen dinlenik enerji harcamasının çok az değiştiği $(<\% 5)$, dört katılımcıda arttığı, 10 katılımcıda düştüğü rapor edilmiştir (6). Bunun yanı sıra, Levine ve ark. (7) oturur pozisyonda ve ayakta ölçülen enerji harcaması arasındaki farkın bireysel olarak çok büyük değişkenlik gösterdiğini ve \%0-25 arasında değiştiğini saptamışlardır.

Bu bulgular postüral değişimin neden olduğu enerji maliyeti ile ilgili farklı fenotiplerin var olduğunu ve enerji harcamasının bireysel olarak değiştiğini göstermektedir. $\mathrm{Bu}$ nedenle DMH'nin hangi vücut pozisyonunda doğru ve güvenilir ölçüleceği tartışmalıdır. Postüre bağlı olarak ortaya çıkan iki temel fizyolojik değişiklik metabolik hızdaki artışın nedeni olarak kabul edilmektedir. Söz konusu iki fizyolojik değişiklikten biri kalp atım hızındaki artış (8), diğeri ise antigravitasyonel kasların (postür kaslarının) aktivitesindeki artıştır (9). Yatar pozisyonla karşılaştırıldığında, ayakta ölçülen kalp atım hızı ve postüral kas aktivitesinin önemli ölçüde arttığı gösterilmiştir (9). Postüral değişime bağlı olarak ortaya çıkan bu 
değişimlerin her ikisinin de DMH'de (oksijen tüketiminde) artışa neden olduğu kabul edilmekle birlikte, postüral değişimin $\mathrm{DMH}$ üzerindeki etkisine ilişkin çalışmaların sonuçları çelişkilidir. Bazı çalışmalarda vücut pozisyonunun DMH'yi etkilemediği $(8,10,11)$; diğer çalışmalarda ise yatar pozisyonla karşılaştırıldığında ayakta ölçülen DMH'nin anlamlı derecede yüksek olduğu rapor edilmiștir $(7,12)$.

Bunun yanı sıra, postürdeki değişime bağlı olarak dinlenik enerji metabolizmasında kullanılan yakıt tipinde ne gibi değişiklikler olduğuna dair bilgi de sınırlıdır. Genç erkek ve kadınlarda yapılan bir çalışmada oturur pozisyonla karşılaştırıldığında, ayakta ölçülen solunum değişim oranının (SDO) anlamlı derecede düşük olduğu saptanmıştır (6). SDO ve plazma serbest yağ asit (SYA) konsantrasyonu arasında anlamlı negatif ilișkinin varlığı (13) ve SYA kullanım hızı arttıkça SDO'nun düşmesi (14), postüral değişime bağlı olarak ayakta dinlenik enerji harcaması esnasında yakıt seçiminin karbonhidratlardan serbest yağ asitlerine kaydığının bir göstergesi olarak kabul edilebilir.

$\mathrm{Bu}$ doğrultuda bu çalışmanın amacı, sedanter genç erkeklerde postürün (yatar, oturur ve ayakta) DMH ve yakıt kullanımı üzerindeki etkisini araştırmak, farklı postürlerde ölçülen dinlenik $\mathrm{VO}_{2}$ 'yi 1 MET değeri ile karşılaştırmaktır.

\section{GEREÇ ve YÖNTEMLER}

Katılımcılar: Bu çalışmanın araştırma grubu 18 yaşından büyük, sedanter yaşam alışkanlığında olan (2 saat/haftadan az egzersiz yapan), sigara kullanmayan, alt ekstremite sakatlık öyküsü bulunmayan ve herhangi bir medikal destek almayan 23 erkek (Yaş: $26.7 \pm 5.8$ yll, boy: $177.4 \pm$ $6.8 \mathrm{~cm}, \mathrm{VA}: 77.2 \pm 10.9 \mathrm{~kg}$, beden kütle indeksi (BKI): $24.5 \pm 2.9$ kg.m² ${ }^{2}$, vücut yağ yüzdesi (VYY): 19.4 $\pm 5.1 \%$, yağsız vücut kütlesi (YVK): 61.8 \pm 5.6 $\mathrm{kg}$ ) katılımcıdan oluşturuldu. Katılımcıların fiziksel aktivite durumunu belirlemek için Uluslararası Fiziksel Aktivite Anketi (kısa form) kullanıldı. Katılımcılara çalışma hakkında ayrıntılı bilgi verildi ve testlerden 24 saat önce yüksek şiddette fiziksel aktivite yapmamaları, en az 12 saat öncesinde alkollü ve kafeinli yiyecek ya da içecek tüketmemeleri, en az 8 saat uyumaları ve bir gecelik açlık sonrasında laboratuvara gelmeleri istendi. Araştırma için Hacettepe Üniversitesi Girişimsel Olmayan Klinik Araştırmalar Etik Kurulu'ndan izin alındı (Karar No: G0 17/770-01).

Vücut kompozisyonu: Boy uzunluğu duvara monte stadiyometrede (Holtain Ltd., İngiltere), VA elektronik baskülde (Tanita TBF 401A, Japonya) ölçüldü. Vücut yağ yüzdesi (VYY) ayaktan ayağa biyoelektrik empedans analizöründe (Tanita TBF 401A, Japonya) belirlendi. Bunun için katılımcıların kişisel bilgileri analizöre kayıt edildikten sonra çıplak ayakla analizörün tablasında bulunan elektrotlar üzerine basarak hareketsiz durmaları istendi. VYY ve YVK analizörde otomatik olarak hesaplandı ve yazıcıdan çıktı olarak alındı.

Dinlenik metabolik hız: DMH, laboratuvar ortamında (sıcaklık $21.3 \pm 2.1{ }^{\circ} \mathrm{C}$, nem $35.3 \pm 8.6 \%$ ) her ekspirasyon havasından ölçüm yapan otomatik gaz analiz sistemi (Quark b2, Cosmed, İtalya) ile belirlendi. Tüm ölçümler bir gece açlık sonrasında sabah saat 09:00-10:00 arasında tamamlandı. Katılımcılar antropometrik ölçüm sonrasında en az $30 \mathrm{dk}$ oturur pozisyonda dinlendirildikten sonra, rastgele sira ile yatar pozisyonda, oturur pozisyonda ve ayakta $10 \mathrm{dk}$ süre (6) ile dinlenik oksijen tüketimi $\left(\mathrm{VO}_{2}\right)$, karbondioksit üretimi $\left(\mathrm{VCO}_{2}\right)$, dakika ventilasyonu $\left(\mathrm{V}_{\mathrm{E}}\right)$ ve kalp atım hızı (KAH) ölçüldü. KAH oksijen analiz sistemi ile entegre telemetrik KAH monitörü (Polar, Finlandiya) ile ölçüldü.

Yatar pozisyondaki ölçümler, katılımcı bir masaj masasına sırtüstü yatırılarak; oturur pozisyondaki ölçümler, yüksekliği ayarlanabilir standart bir ofis sandalyesinde dizler $90^{\circ}$ açıda ayaklar yere basarken ve gövde uyluk ile $90^{\circ}$ açı yapacak şekilde dik pozisyonda otururken; ayaktaki ölçümler, ayaklar omuz genişliğinde açık pozisyonda, vücut ağırlığı her iki bacağa dağıtılmış halde ve kıpırdamadan yapıldı. Her ölçümden önce oksijen ve karbondioksit analizörleri içerisinde konsantrasyonu bilinen

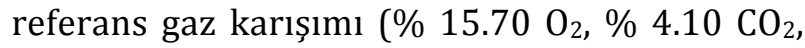
$\mathrm{N}_{2}$ balans) kullanılarak üretici firma yönergesi 
doğrultusunda kalibre edildi. Analiz sisteminin türbin kalibrasyonu için 3.0 l sertifikalı şırınga (Cosmed, İtalya) kullanıldı. İlk 5 dk kayıt edilen veri ölçüm ortamına ve sisteme alıșma olarak kabul edilerek değerlendirme dıșı bırakıldı ve son $5 \mathrm{dk}$ DMH'nin değerlendirilmesinde kullanıldı. Her postürde ölçülen dinlenik $\mathrm{VO}_{2}$ ve $\mathrm{VCO}_{2}$ değerlerinden aşağıdaki formül (Weir, 1949) kullanılarak kcal.dk ${ }^{-1}$ cinsinden DMH hesaplandı:

kcal.dk-1 $=3.941 \mathrm{VO}_{2}+1.106 \mathrm{VCO}_{2}$

Postüre bağlı olarak enerji metabolizmasında yakıt kullanımındaki değişim ise aşağıdaki formüllerle hesaplandı (Frayn, 1983):

$\mathrm{KH}\left(\mathrm{g} \cdot \mathrm{dk}^{-1}\right)=4.55 \mathrm{VCO}_{2}\left(\mathrm{l} . \mathrm{dk}^{-1}\right)-3.21 \mathrm{VO}_{2}\left(\mathrm{l}^{\mathrm{dk}} \mathrm{dk}^{-1}\right)$ SYA $\left(\right.$ g.dk $\left.{ }^{-1}\right)=1.67 \mathrm{VO}_{2}\left(\mathrm{l}^{-\mathrm{dk}^{-1}}\right)-1.67 \mathrm{VCO}_{2}\left(\mathrm{l}^{-1 \mathrm{dk}^{-1}}\right)$

\section{Verilerin analizi}

Tüm değişkenlerin normal dağılıma uyumu Kolmogorov-Smirnov testi ile kontrol edildi. Tüm değișkenler için normal dağılımdan sapma anlamlı değildi $(p>0.05)$. Postüral değişimin $\mathrm{DMH}, \mathrm{V}_{\mathrm{E}}, \mathrm{VO}_{2}, \mathrm{KAH}, \mathrm{SDO}$ ve yakıt kullanımı üzerindeki etkisini belirlemek için tekrarlı ölçümlerde ANOVA kullanıldı. F istatistiği anlamlı çıktığında farkın hangi postürden kaynaklandığı Bonferonni post hoc test ile belirlendi. Tekrarlı ölçümlerde küresellik varsayımının geçerliği Mauchly testi ile saptandı. Küresellik varsayımı yerine gelmeyen değişkenlerde epsilon $(\varepsilon)<0.75$ ise Greenhouse-Geisser, $>0.75$ ise Huynh-Feldt düzeltmesi uygulandı (15). Farklı postürlerde dinlenik $\mathrm{VO}_{2}$ 'nin 1 MET değerinden farkı için tek örneklem t-testi kullanıldı. İstatistiksel işlemler Windows için SPSS (v. 15.0) programıla yapıldı ve anlamlılık düzeyi $\mathrm{p}<0.05$ olarak kabul edildi.

\section{BULGULAR}

Yatar, oturur pozisyonda ve ayakta $\mathrm{V}_{\mathrm{E}}$ ve $\mathrm{KAH}$ 'daki değişimler Şekil $1 \mathrm{~A}$ ve $1 \mathrm{~B}^{\prime}$ de gösterilmektedir. Postüral değişimin $V_{E}$ ve KAH üzerine etkisi anlamlı bulundu $\left(\mathrm{V}_{\mathrm{E}}\right.$ için $\mathrm{F}_{(1.47 ; 44)}=38.0, \mathrm{p}<0.001$; $\mathrm{KAH}$ için $\left.\mathrm{F}_{(1.27 ; 44)}=79.7, \mathrm{p}<0.001\right)$. Her üç postürde hem $V_{E}(p<0.01)$, hem de KAH $(p<0.01)$ birbirinden anlamlı derecede farklıydı. En düşük $\mathrm{V}_{\mathrm{E}}$ ve $\mathrm{KAH}$ yatar pozisyonda, en yüksek ayakta ölçüldü (Şekil $1 \mathrm{~A}$ ve $1 \mathrm{~B}$ ). $\mathrm{V}_{\mathrm{E}}$, yatar pozisyonla karşılaştırıldığında oturur pozisyonda yaklaşık $\% 10$, ayakta $\% 24$ daha yüksekti. Şekil 2 postüral değişime bağlı olarak DMH'de meydana gelen değişimi göstermektedir. Postüral değişimin DMH üzerindeki etkisi anlamlı bulundu $\left(\mathrm{F}_{(1.71 ; 44)}=13.9\right.$, $\mathrm{p}<0.001$ ). Yatar ve oturur pozisyonda ölçülen $\mathrm{DMH}$ benzer $(\mathrm{p}>0.05)$, her ikisi ayakta ölçülenden anlamlı derecede düșüktü $(\mathrm{p}<0.01)$ (Şekil 2). Yatar pozisyona göre DMH oturur pozisyonda \%4.5, ayakta \%17 oranında yüksekti.

Şekil 3A ve 3B'de postüral değişime bağlı olarak ölçülen SDO ve yakıt kullanımındaki değişimler verilmektedir. SDO postüre bağlı olarak anlamlı derecede değişti $\quad\left(\mathrm{F}_{(1.44 ; 44)}=12.9, \quad \mathrm{p}<0.001\right)$. Oturur pozisyonda ve ayakta ölçülen SDO benzeri $(p>0.05)$; her ikisi yatar pozisyondan anlamlı derecede düşüktü $(\mathrm{p}<0.01)$ (Şekil $3 \mathrm{~A})$. Oturur pozisyonda ve ayakta ölçülen SDO yatar pozisyona göre sırasıyla \%3.4 ve $\% 4.5$ düşüktü. Benzer șekilde; KH ve SYA kullanım hızı üzerine de postürün etkisi anlamlı bulundu (KH için $\mathrm{F}_{(1.65 ; 44)}=3.53$, $\mathrm{p}<0.05$; SYA için $\mathrm{F}_{(1.39 ; 44)}=25.9$, $\mathrm{p}<0.001)$. Ayakta ölçülen KH kullanım hızı yatar ve oturur pozisyonda ölçülene benzer ( $p>0.05)$; fakat yatar pozisyonda oturur pozisyondan anlamlı derecede yüksekti $(\mathrm{p}<0.05)$ (Şekil 3B). Yatar pozisyonla karşılaştırıldığında, oturur pozisyonda KH kullanım hızı \%17.4, ayakta \%14.5 oranında azalmıștı. Buna karşılık SYA kullanım hızı üç pozisyonda da anlamlı derecede birbirinden farklı idi $(\mathrm{p}<0.001)$ (Şekil 3B). En düşük SYA kullanım hızı yatar pozisyonda, en yüksek ayakta ölçüldü. Yatar pozisyona göre SYA kullanım hızı oturur pozisyonda $\% 25.4$, ayakta $\% 47.3$ oranında yüksekti.

Postüral değişime bağlı olarak ölçülen dinlenik rölatif $\mathrm{VO}_{2}$ değerlerinin 1 MET'e göre değișimi Şekil 4'te gösterilmektedir. Yatar $(2.72 \pm 0.58$ ml. $\left.\mathrm{dk}^{-1} . \mathrm{kg}^{-1}\right)$ ve oturur $\left(2.89 \pm 0.75 \mathrm{ml} . \mathrm{dk}^{-1} \cdot \mathrm{kg}^{-1}\right)$ pozisyonda ölçülen dinlenik $\mathrm{VO}_{2}$ değeri 1 MET (3.5 ml.dk ${ }^{-1} . \mathrm{kg}^{-1}$ ) değerinden anlaml derecede düşük (yatar pozisyon için $\mathrm{t}_{(22)}=8.38$; $\mathrm{p}<0.001$, oturur pozisyon için $\mathrm{t}_{(22)}=3.90 ; \mathrm{p}<0.01$ ); ayakta

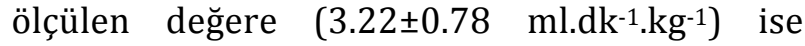
benzer bulundu $\left(\mathrm{t}_{(22)}=1.70 ; \mathrm{p}>0.05\right)$. Yatar, oturur pozisyonda ve ayakta ölçülen dinlenik $\mathrm{VO}_{2}$ 1 MET değerinden sirasıyla $\% 22.3, \% 17.4$ ve \%8.0 daha düşüktü. 
A

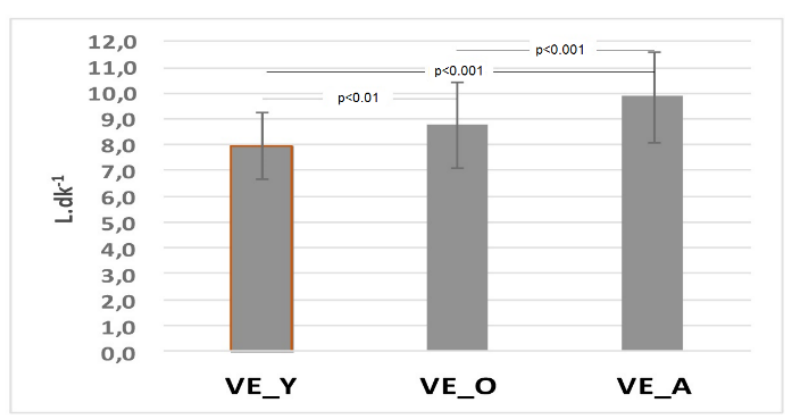

B

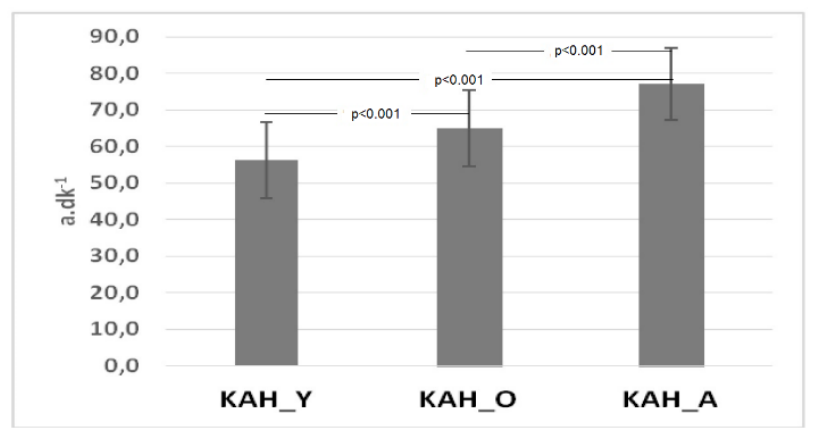

Şekil 1. Postüre bağlı olarak $V_{E}(A)$ ve KAH'daki (B) değişimler. Postüral değişimin $V_{E}$ ve KAH üzerine etkisi anlamlı bulundu $(\mathrm{p}<0.001)$. Her bir postürde ölçülen $\mathrm{V}_{\mathrm{E}}$ ve $\mathrm{KAH}$ 'lar anlamlı derecede birbirinden farklıydı. Y: yatar pozisyon, O: oturur pozisyon, A: ayakta.

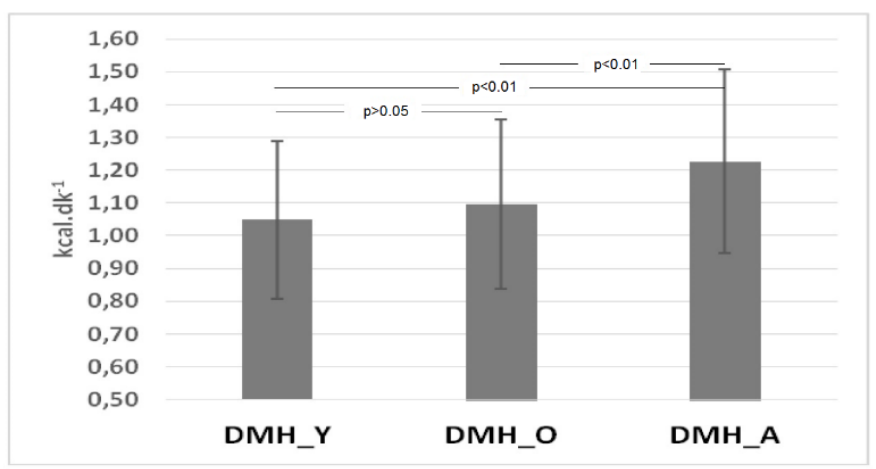

Şekil 2. Postüre bağlı olarak DMH'daki değișimler. Yatar ve oturur pozisyonda dinlenik enerji harcaması benzerdir $(\mathrm{p}>0.05)$. Ayakta enerji maliyeti yatar ve oturur pozisyona göre önemli ölçüde yükselmiştir $(\mathrm{p}<0.01)$.

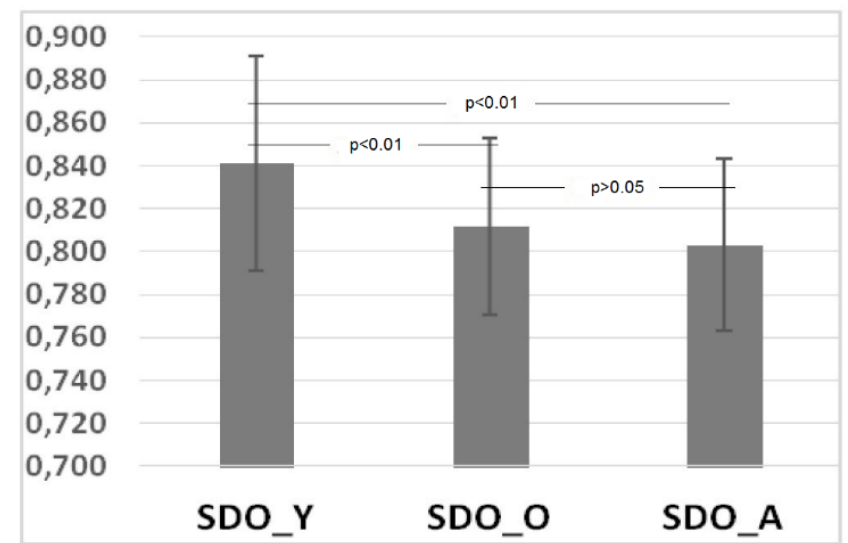

A

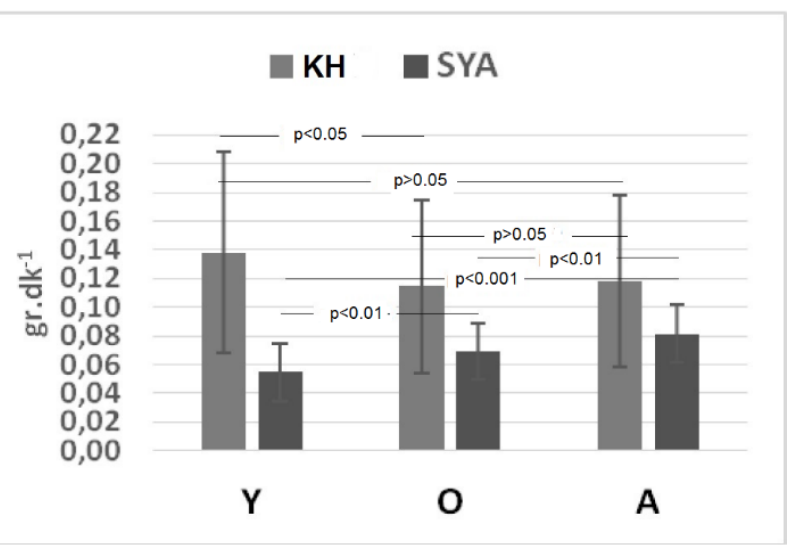

B

Şekil 3. Postüral değişimin SDO (A) ve yakıt kullanımına (B) etkisi. SDO, oturur pozisyonda ve ayakta benzer ( $p>0.05)$, her ikisi yatar pozisyondan anlamlı derecede düşüktü $(\mathrm{p}<0.05)$. Yatar pozisyondan ayağa doğru SDO'da düşüş yakıt kullanımının KH'dan SYA'ya kaydığını göstermektedir. 


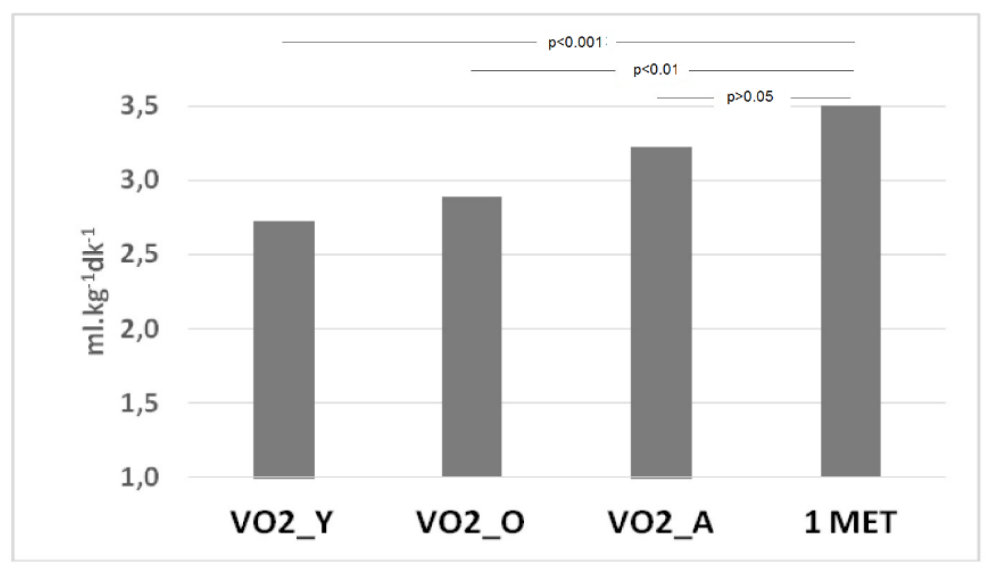

Şekil 4. Farklı postürlerdeki dinlenik rölatif $\mathrm{VO}_{2}$ değerlerinin 1 MET'e göre değişi$\mathrm{mi}$. Yatar ve oturur pozisyonda rölatif dinlenik $\mathrm{VO}_{2} 1 \mathrm{MET}$ değerinden anlamlı derecede düşük $(p<0.01)$ ancak ayakta ölçülen benzerdir $(p>0.05)$.

\section{TARTIȘMA}

Önceki çalışmalarda genel olarak yatar-ayakta veya yatar-oturur pozisyon olmak üzere vücut pozisyonunun iki durumunun DMH üzerine etkisi incelenmiştir. Bu çalışmada üç farklı postürün DMH üzerine etkisi ve postüral değişime bağlı olarak dinlenik yakıt kullanımının nasıl değiştiği incelenmiştir. $\mathrm{Bu}$ çalışmanın ana bulgusu, postüral değişimin DMH'yi ve dinlenik yakıt kullanımını önemli ölçüde etkilediğini göstermiştir. Ayakta ölçülen DMH yatar ve oturur pozisyonda ölçülenden anlamlı derecede yüksek bulunmuştur (Şekil 2). Ayrıca yatar pozisyondan ayakta duruşa doğru vücut pozisyonundaki değişim yakıt metabolizmasının KH'den serbest yağ asitlerine kaydığını gösterdi (Şekil 3B). KAH ve $V_{\mathrm{E}}$ 'de postüre bağlı olarak anlamlı değişimler gözlendi. Hem KAH hem de $\mathrm{V}_{\mathrm{E}}$ her üç postürde de birbirinden anlaml derecede farklı idi (Şekil 1A ve B).

Postür yatar pozisyondan ayakta sabit duruşa doğru değiştikçe $K A H$ ve $V_{E}$ önemli derecede artmış bulundu. Bu bulgular önceki çalışmaların bulgularına benzerdir $(10,16,17,18)$. En düşük KAH'nin yatar pozisyonda, en yüksek değerin ise ayakta ölçülmesi yer çekiminin doğrudan etkisi ile açıklanabilir. İnsan vücudu üzerinde yer çekiminin etkisi postüre bağlı olarak değişir ve özellikle vücut sıvılarının dağılımı yeniden düzenlenir (19). Postüral değişimle birlikte yer çekiminin vücut üzerindeki etkisinin değişmesi, dokulara oksijen taşınmasını olumsuz etkiler ve optimal kan akımını ve oksijen transferini sağlamak için kardiyopulmoner sistemin işlevi değişir $(15,16)$. Yatar pozisyondan ayakta duruşa doğru postüral değişim sonucunda alt ekstremite ile kalp arasındaki kan akımı yatay konumdan dikey konuma gelir. İnsanda tüm kan hacminin yaklaşık \%70'i sistemik venlerde bulunur ve yatar pozisyondan kalkıldığında bacaklardaki venöz kan yaklaşık $500 \mathrm{ml}$, ek olarak kalça ve pelvik alanda da 200-300 ml civarında artar (19). Yer çekiminin etkisi ile venöz kan dağılımındaki bu değişim sonucunda venöz dönüş ve diastol sonu ventrikül hacmi azalır (15). Bu durum baroreseptörlerde basincın azalmasina neden olur ve merkezi sinir sisteminde üst merkezler uyarılarak KAH arttırılır. Böylece alt ekstremitelerde birikmiş olan kanın büyük dolaşıma girmesi sağlanır (15).

Bunun yanı sıra hem kalp kasının, hem de postür kaslarının aktivitesindeki artış nedeniyle vücudun oksijen ihtiyacı artar ve buna bağlı olarak pulmoner ventilasyonda (yani $V_{E}^{\prime}$ de) önemli değişim gözlenir. Bu çalışmada postürdeki değişime bağlı olarak $V_{E}$ 'de gözlenen değiş̧imler önceki çalışmalarda elde edilen bulgulara benzerdir. Yatar pozisyonla karşılaştırıldığında ayakta ölçülen $V_{E}$ 'nin önemli ölçüde arttığı ancak 
solunum frekansının postürden bağımsız olduğu rapor edilmiştir $(6,10,17)$.

$\mathrm{Bu}$ çalışmada yatar pozisyondan oturur pozisyona geçildiğinde enerji maliyetinde anlamlı bir değișim gözlenmezken, ayakta duruş esnasında enerji harcaması diğer iki pozisyonda ölçülenden anlamlı derecede yüksek bulundu (Şekil 2). Postürün DMH üzerine etkisi ile ilgili çalışmalarda elde edilen bulgularda çelişkiler vardır. Örneğin bu çalışmanın aksine Leik ve ark. (11) ve Seedhouse (8) çalışmalarında yatar pozisyonda ve ayakta ölçtükleri oksijen tüketimi arasında önemli fark saptamamışlardır. Buna karşllık Chang ve ark. (17) ve Terkelsen ve ark. (20) çalışmalarında, bu çalışmada olduğu gibi yatar pozisyonla karşılaştırdıklarında, ayakta ölçülen oksijen tüketiminde anlamlı artış rapor etmişlerdir. Ek olarak bu çalışmada yatar ve oturur pozisyonda ölçülen DMH'nin benzer olması daha önce yapılan iki çalışmanın sonuçları ile uyumludur. Levine ve ark. (7) hareketsiz oturur pozisyonda ölçtükleri enerji harcamasını yatar pozisyondan farklı bulmamışlardır. Yakın zamanda yapılan bir diğer çalışmada da (10) dokuz erkek ve 10 kadında yatar pozisyonla karşılaştırıldığında, oturur pozisyonda enerji harcamasının istatistiksel olarak anlamlı olmayan derecede arttığı $(<\% 2.0)$ gösterilmiştir.

Levine ve ark. (7) postüral değişime bağlı olarak yatar pozisyonla karşılaştırdıklarında, enerji harcamasını hareketsiz otururken \%4, otururken kımıldandığında \%54; ayakta hareketsiz \%13 ve ayakta kımıldandığında \%94 oranında anlamlı derecede arttığını göstermişlerdir. Her iki cinste yapılan bir diğer çalışmada da, yatar pozisyonla karşılaştırıldığında oturur pozisyonda $\mathrm{DMH}$ erkeklerde \%25, kadınlarda \%13; ayakta erkeklerde \%43, kadınlarda \%23 daha yüksek ölçülmüştür (12). Bu çalışmada yatar-oturur ve yatar-ayakta şeklindeki postüral değişime bağlı olarak enerji harcamasındaki oransal değișimler Levine ve ark.'nın (7) çalışmasındaki değerlere benzer, ancak Kanade ve ark.'nın (12) değerlerinden belirgin miktarda düşüktü. Yatar ya da oturur pozisyona göre ayakta dururken enerji harcamasındaki artış, postürün korunması için antigravitasyonel kasların refleksif aktivitelerindeki artışa ve ortostatik strese bağlı olarak kan akımının yeniden düzenlenmesi nedeniyle kardiyopulmoner sisteme ait kasların (KAH ve $\mathrm{V}_{\mathrm{E}}$ 'de artış) aktivitelerindeki artışlara bağlanmaktadır.

Bu çalışmada ölçülmemiş olmakla birlikte, yatar pozisyonla karşılaştırıldığında, ayakta dururken alt ekstremite postür kaslarında (soleus ve gastrocnemius) elektromyografik (EMG) aktivitenin daha yüksek olduğu ve EMG aktivitesi ile DMH arasında pozitif ilişki bulunduğu gösterilmiștir (9). Bununla birlikte aynı çalışmada kardiovasküler değişkenler ve DMH arasında anlamlı ilişkiler saptanmamıştır. $\mathrm{Bu}$ bulgular postüre bağlı olarak DMH'daki artışın öncelikli olarak antigravitasyonel kasların aktivite artışından kaynaklandığını göstermektedir.

Literatürde postüral değişime bağlı olarak enerji metabolizması yakıtlarındaki değişime ilişkin doğrudan bilgiye rastlanmamıştır. Bununla birlikte, Miles-Chan ve ark. (10) çalışmalarında enerji harcamasında fark bulmamış olmalarına karşın, oturur pozisyonda ölçtükleri SDO'nun yatar pozisyondan anlamlı derecede düşük olduğunu rapor etmişlerdir. Bu çalışmada da oturur ve ayakta ölçülen SDO yatar pozisyondan anlamlı derecede düşüktür. SDO'nun yatar pozisyona göre oturur pozisyonda ve ayakta daha düşük olması, metabolizmada SYA'ların baskın yakıt olduğunun bir göstergesi olarak kabul edilebilir (14). Bu çalışmada yatar pozisyonda KH kullanımı oturur ve ayakta duruş esnasında kullanılandan yüksek olmasına karşın, sadece oturur pozisyonda kullanılan $\mathrm{KH}^{\prime} \mathrm{den}$ anlamlı derecede yüksek bulundu. Buna karşılık, KH kullanımının en yüksek olduğu yatar pozisyonda SYA kullanımı en düşük düzeyde iken, oturur pozisyonda anlamlı derecede artmıştı. Ayakta SYA kullanım hızının da oturur pozisyondan anlamlı derecede yüksek olması, postüral kaslar aktifleştikçe postüral temel enerji kaynağının SYA'lar olduğunu göstermektedir.

Yatar pozisyonda antigravitasyonel kasların EMG aktivitesinin diğer pozisyonlara göre minimal düzeyde olması (9) ve bu çalışmada gösterildiği üzere $\mathrm{KH}$ kullanımının yüksek olması, yatar pozisyonda DMH'nin büyük oranda sinir sistemi ve iç organların aktivitelerine bağlı enerji 
harcamasından kaynaklandığını ve bu harcamanın da KH'ye dayalı olduğunu düşündürmektedir. Her ne kadar iskelet kas kitlesi diğer doku ve organlarla karșlaștırıldığında vücut ağırlığının büyük bölümünü olușturuyorsa da, dinlenik şartlarda iç organların metabolik hızları ile karșılaștırıldığında metabolik hızı düșük bir dokudur (21). Beyin, kalp, karaciğer ve böbrek gibi organların metabolik hızı 200-440 kcal.gün1 .kg-1, buna karşıllık iskelet kaslarınınki 13-15 kcal.gün-1.kg-1 civarındadır (22). Bu nedenle, metabolik hızı yüksek organların toplam ağırlığı tüm vücut ağırlığının \%5-6'sına karşllk gelmesine karşın, bu organların enerji harcaması DMH'nin \%70-85'ini oluşturmaktadır (21).

Diğer organlardan farklı olarak, özellikle merkezi sinir sisteminde nöron ve astrositlerin enerji metabolizmasının aerobik metabolizmaya; yakıt seçimi ve kullanımının da doğrudan glükoz ve glükoz kökenli laktik asite (23-25) dayanması, yatar pozisyonda KH kullanımının yüksek olmasina bir delil olarak kabul edilebilir. Bunun yanı sıra, yatar pozisyondan ayakta duruşa doğru postüral değişimin neden olduğu SYA kullanım hızındaki artış, muhtemelen antigravitasyonel kas aktivitesi artışından kaynaklanmaktadır. Dinlenik durumla karşılaştırıldığında, düşük şiddette uzun süreli egzersiz esnasında beyinde kan akımının benzer olması, merkezi sinir sisteminde oksijen tüketiminin ve KH'ye dayalı enerji harcamasının değişmediğini gösterir (26). Böylece bu bulgu, yatar pozisyona göre ayakta DMH'de artışın merkezi sinir sistemi aktivitesi artışından daha ziyade antigravitasyonel kas aktivitesinden kaynaklandığı görüşünü destekler. Ayakta ölçülen DMH içinde merkezi sinir sisteminden kaynaklanan enerji harcamasının ve buna bağlı olarak yakıt kullanımının değişmemesi (KH kullanımı), SYA kullanımındaki artışın antigravitasyonel kas aktivitesinin bir sonucu olduğu görüşünü kuvvetlendirmektedir.

Ek olarak, antigravitasyonel kaslarda yavaş kasılan (Tip I) kas fibril yüzdesi yüksektir (27-29). Tip I fibrillerin aerobik enerji metabolizması ve SYA kullanım hızının diğer fibril tiplerinden yüksek olması (30), antigravitasyonel kas aktivitesi arttığında neden SYA kullanımının da arttığını kısmen açıklayabilir.

Bir birim MET, sandalyede sessizce otururken ölçülen oksijen tüketimi olarak tanımlanmakta ve DMH olarak kabul edilmektedir (31). Bir MET değerinin karşılı̆̆ tüketiminin DMH'yi temsil etmediği ve yüksek bir değer olduğuna dair bulgular mevcuttur (3235). Bu çalışmada farklı postürlerde ölçülen DMH'nin 1 MET ile ne oranda örtüştügü de incelendi. Yatar ve oturur pozisyonda ölçülen dinlenik $\mathrm{VO}_{2}$ değerleri 1 MET'den sirasiyla \%23 ve \%24 oranında düşük ve istatistiksel olarak anlamlı derecede farklıdır. Buna karşılık, ayakta ölçülen dinlenik $\mathrm{VO}_{2} 1$ MET değerinden \%11 oranında düşük olmakla birlikte, istatistiksel olarak farklı değildi. Ayakta ölçülen DMH'nin diğer postürlerden anlamlı derecede yüksek, ancak 1 MET değerine

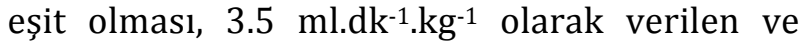
DMH'yi temsil eden bu değerin yüksek olduğuna delil olarak kabul edilebilir.

Bu çalışmanın başlıca sınırlılı̆̆ $\mathrm{DMH}$ ölçümünün benzetilmiş olması, yani bir başka deyişle yarı deneysel bir modelin kullanılmasıdır (Quasiexperimental model). DMH'nin belirlenmesi için kullanılan ölçüm süresi 20-60 dk gibi çok geniş bir aralıkta değişmektedir. Bu çalışmada DMH $10 \mathrm{dk}$ süreyle $\mathrm{VO}_{2}$ ve $\mathrm{VCO}_{2}$ ölçülerek belirlendiği için, elde edilen enerji harcaması değerleri DMH'yi tam olarak temsil etmeyebilir. Postüral değişimin DMH üzerindeki etkisinin incelendiği benzer çalışmalarda da ölçüm süresi 5-10 dk ile sınırl tutulmuştur. Araştırma modelinde DMH ölçüm süresinin kısa tutulmasının nedeni, ayakta DMH'nin belirlenmesidir. DMH'yi belirlemek için kullanılan ölçüm süreleri bu tip çalışmalarda kullanıldığında, özellikle ayakta yapılan ölçümlerde antigravitasyonel kaslardaki izometrik kasılma nedeniyle egzersiz etkisi yaratacak ve ölçülen enerji harcaması DMH'den uzaklaşacaktır.

Bir diğer sınırlılık ise postüre bağlı olarak antigravitasyonel kas aktivitelerindeki değişimin gösterilmemiş olmasıdır. EMG ölçümleriyle kas aktivitesindeki değişimlerin gösterilmesi postüral değişimin neden olduğu enerji maliyetindeki artışı destekleyici olabilir. Her ne kadar bu ve önceki çalışmalarda dinlenik durumda postüral 
değişimin enerji maliyetinde önemli artışa neden olduğu gösterilmişse de, bireysel olarak incelendiğinde enerji maliyetinin farklı fenotipik özellikler gösterdiği, bir başka deyiş̧le bireyler arasında büyük değișkenlikler sergilediği saptanmıştır $(6,7)$. Bu çalışmada da bireysel seviyede enerji maliyeti incelendiğinde; yatar pozisyondan oturur pozisyona geçildiğinde 23 katılımcıdan 10'unda (\%43.4) DMH düşmüștür. DMH'deki düşüş \%1.8-18.0 gibi geniş bir aralıkta değişmektedir. Benzer şekilde, artış gözlenen katılımcılar arasında da \%1.2-56.2 gibi geniş bir değişim gözlenmektedir. Yatar pozisyondan ayakta duruşa geçildiğinde de katılımcıların \%17'sinde (4/23 katılımcı) DMH daha düşük ölçüldü (\%0.9-17.1). Diğer katılımcılarda ayakta DMH artışı yatar pozisyonla karşılaştırıldığında \%0.9-61.8 gibi geniş bir aralık söz konusudur. Oturur pozisyona göre ayakta DMH düzeyi iki katılımcıda azalmış, bir katılımcıda ise değişmemiştir. DMH'deki artış \%1.7-36.9 aralığındadır. Sadece bir katılımcıda yatar pozisyondan ayakta duruşa doğru tüm postüral değişimler esnasında enerji maliyeti azalmış, \%47.8'inde sürekli olarak artmıştır. Bu bulgular Miles-Chan ve ark.nın (6) bulgularına benzerlik göstermektedir.

\section{SONUÇ}

Bu çalışmanın bulguları DMH'nin postüre bağlı olarak önemli ölçüde değiştiğini ve postür kasları devreye girdikçe dinlenik enerji harcamasının karbonhidrattan serbest yağ asitlerine doğru kaydığını göstermektedir. Ayrıca yatar ve oturur pozisyonda $\mathrm{VO}_{2}$ olarak ölçülen DMH'nin standart 1 MET değerinden düșük, ayakta ölçülenin ise 1 MET'e eşdeğer olduğu gözlenmiştir. Bununla birlikte postür ile DMH arasındaki ilişkinin net olarak açıklanmasına yönelik olarak katılımcı sayısının yüksek olduğu kapsamlı çalışmalara gereksinim vardır.

\section{KAYNAKLAR}

1. Weir JB. New methods for calculating metabolic rate with special reference to protein metabolism.J Physiol. 1949;109(1-2):1-9.

2. Frayn KN. Calculation of substrate oxidation rates in vivo from gaseous exchange. J Appl Physiol Respir Environ Exerc Physiol. 1983;55(2):628-34.
3. Speakman JR, Selman C. Physical activity and resting metabolic rate. Proc Nutr Soc. 2003;62(3):621-34.

4. Cunha FA, Midgley AW, Monteiro WD, et al. Influence of cardiopulmonary exercise testing protocol and resting $\mathrm{VO}_{2}$ assessment on \%HRmax, \%HRR, $\% \mathrm{VO}_{2}$ max and $\% \mathrm{VO}_{2} \mathrm{R}$ relationships. Int J Sports Med. 2010;31(5):319-26.

5. Compher C, Frankenfield D, Keim N, et al. Best practice methods to apply to measurement of resting metabolic rate in adults: a systematic review. $J \mathrm{Am}$ Diet Assoc. 2006;106(6):881-903.

6. Miles-Chan JL, Sarafian D, Montani JP, et al. Heterogeneity in the energy cost of posture maintenance during standing relative to sitting: phenotyping according to magnitude and time-course. PLoS One. 2013;8(5):e65827.

7. Levine JA, Schleusner SJ, Jensen MD. Energy expenditure of nonexercise activity. Am J Clin Nutr. 2000;72(6):1451-4.

8. Seedhouse EL. Cardiovascular and metabolic responses to $6^{\circ}$ head-down (HDT) tilt and $70^{\circ}$ headup (HUT) tilt following exercise. Physiologist. 1993; 36(1 Suppl):S58-61.

9. Rubini A, Paoli A, Parmagnani A. Body metabolic rate and electromyographic activities of antigravitational muscles in supine and standing postures. Eur J Appl Physiol. 2012;112(6):2045-50.

10. Miles-Chan JL, Sarafian D, Montani JP, et al. Sitting comfortably versus lying down: is there really a difference in energy expenditure? Clin Nutr. 2014; 33(1):175-8.

11. Leik D, Essfeld D, Hoffmann U, et al. Postural effect on cardiac output, oxygen uptake and lactate during cycle exercise of varying intensity. Eur J Appl Physiol Occup Physiol. 1994;68(1):30-5.

12. Kanade AN, Gokhale MK, Rao S. Energy costs of standard activities among Indian adults. Eur J Clin Nutr. 2001;55(8):708-13.

13. Jensen MD, Bajnárek J, Lee SY, et al. Relationship between postabsorptive respiratory exchange ratio and plasma free fatty acid concentrations. J Lipid Res. 2009;50(9):1863-9.

14. Schiffelers SL, Saris WH, van Baak MA. The effect of an increased free fatty acid concentration on thermogenesis and substrate oxidation in obese and lean men. Int J Obes Relat Metab Disord. 2001;25(1): 33-8.

15. Singer $\mathrm{W}$, OpferGgehrking TL, McPhee BR, et al. Influence of posture on the Valsalva manoeuvre. Clin Sci (Lond). 2001;100(4):433-40.

16. Jones AY, Dean E. Body position change and its effect on hemodynamic and metabolic status. Heart Lung. 2004;33(5):281-90.

17. Chang AT, Boots RJ, Brown MG, et al. Ventilatory changes following head-up tilt and standing in healthy subjects. Eur J Appl Physiol. 2005;95(5-6):409-17. 
18. Yoshizaki H, Yoshida A, Hayashi F, et al. Effect of posture change on control of ventilation. Jpn J Physiol. 1998;48(4):267-73.

19. Blomqvist CG, Stone HL. Cardiovascular Adjustments to gravitational stress. Handbook of Physiology, the Cardiovascular System, Peripheral Circulation and Organ Blood Flow (Suppl 8). Compr Physiol. 2011;1025-63.

20. Terkelsen KE, Clark AL, Hillis WS. Ventilatory response to erect and supine exercise. Med Sci Sports Exerc. 1999;31(10):1429-32.

21. Müller MJ, Bosy-Westphal A, Kutzner D, et al. Metabolically active components of fat-free mass and resting energy expenditure in humans: recent lessons from imaging technologies. Obes Rev. 2002;3(2):11322.

22. Wang Z, Ying Z, Bosy-Westphal A, et al. Specific metabolic rates of major organs and tissues across adulthood: evaluation by mechanistic model of resting energy expenditure. Am J Clin Nutr. 2010;92(6):136977.

23. Tang BL. Brain activity-induced neuronal glucose uptake/glycolysis: Is the lactate shuttle not required? Brain Res Bull. 2017;9(137):225-8.

24. Nortley R, Attwell D. Control of brain energy supply by astrocytes. Curr Opin Neurobiol. 2017;47:80-5.

25. Pellerin L, Bouzier-Sore AK, Aubert A, et al. Activitydependent regulation of energy metabolism by astrocytes: an update. Glia. 2007;55(12):1251-62.

26. Hiura M, Nariai T, Ishii K, et al. Changes in cerebral blood flow during steady-state cycling exercise: a study using oxygen-15-labeled water with PET. J Cereb Blood Flow Metab. 2014;34(3):389-96.

27. Staron RS, Hagerman FC, Hikida RS, et al. Fiber type composition of the vastus lateralis muscle of young men and women. J Histochem Cytochem. 2000;48(5): 623-9.

28. Ng JK, Richardson CA, Kippers V, et al. Relationship between muscle fiber composition and functional capacity of back muscles in healthy subjects and patients with back pain. J Orthop Sports Phys Ther. 1998;27(6):389-402.

29. Gollnick PD, Sjödin B, Karlsson J. et al. Human soleus muscle: A comparison of fiber composition and enzyme activities with other leg muscles. Pflugers Arch. 1974;348(3):247-55.

30. Schiaffino S, Reggiani C. Fiber types in mammalian skeletal muscles. Physiol Rev. 2011;91(4):1447-531.

31. Jetté M, Sidney K, Blümchen G. Metabolic equivalents (METS) in exercise testing, exercise prescription, and evaluation of functional capacity. Clin Cardiol. 1990;13(8):555-65.

32. Hazır T, Kin İsler A, Köse MG, et al. MET sistemi ve dinlenik metabolik hızın kestirilmesinde Sensewear Pro3 Armband'ın geçerliği. Hacettepe J Sport Sci Spor Bilimleri Dergisi. 2017;28(3):130-36.

33. Kozey S, Lyden K, Staudenmayer J, et al. Errors in MET estimates of physical activities using $3.5 \mathrm{ml} \times \mathrm{kg}(-1) \times$ $\min (-1)$ as the baseline oxygen consumption. J Phys Act Health. 2010;7(4):508-16.

34. Byrne NM, Hills AP, Hunter GR, et al. Metabolic equivalent: one size does not fit all. J Appl Physiol (1985). 2005;99(3):1112-9.

35. Kwan M, Woo J, Kwok T. The standard oxygen consumption value equivalent to one metabolic equivalent $(3.5 \mathrm{ml} / \mathrm{min} / \mathrm{kg})$ is not appropriate for elderly people. Int J Food Sci Nutr. 2004;55(3):179-82. 